\title{
Sensor/actuator fault tolerant sliding mode control for anti-lock braking in a quarter electric vehicle
}

\author{
Bambang L. Widjiantoro, Katherin Indriawati \\ Department of Engineering Physics, Institut Teknologi Sepuluh November, Indonesia
}

\begin{tabular}{l} 
Article Info \\
\hline Article history: \\
Received Dec 4, 2019 \\
Revised Mar 17, 2020 \\
Accepted Apr 23, 2020 \\
\hline
\end{tabular}

Keywords:

Braking system

Fault tolerant control

Observer

Regenerative

Sliding mode control

\begin{abstract}
This paper proposes a scheme to improve regenerative ABS technology that already exists today by adding accommodation faults to the control system. The nominal control algorithm used is a sliding mode control so that system nonlinearities can be handled properly. The proposed method then is called sensor/actuator fault tolerant sliding mode control system. In designing the proposed control, there are two stages, namely estimation of faults, as well as the active mechanism for reconfiguring controls. Estimation of faults is done by using proportional-integral (PI) observers based on extended state space equation. Whereas the control signal reconfiguration is done actively by replacing measured output with their estimates and compensating for control signal using the actuator fault estimate. The simulation shows that the control system based on the proposed algorithm produces better dynamic performance than the sliding mode control (SMC) without fault tolerant feature. Furthermore, the system provides inherent characteristic for dealing with a minor fault in the hydraulic actuator.
\end{abstract}

This is an open access article under the CC BY-SA license.

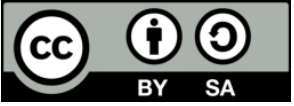

\section{Corresponding Author:}

Katherin Indriawati,

Departement of Engineering Physics,

Institut Teknologi Sepuluh November,

Kampus ITS, Sukolilo, Surabaya 60111, Indonesia.

Email: katherin@ep.its.ac.id

\section{INTRODUCTION}

One important component in the electric vehicle (EV) is the braking system. The modern braking system used to current passenger vehicles is the anti-lock braking system (ABS), because this system can prevent the wheels on the car from being locked when there is emergency braking or sudden braking, so that the car stopping distance will decrease and maneuverability will increase [1]. This system can greatly improve vehicle safety in extreme conditions because ABS can maximize road tire friction while maintaining a large lateral (directional) force that ensures vehicle control [2]. For a variety of road conditions, there is an optimum slip ratio that maximizes the friction coefficient on all road conditions [3]. Therefore, a suitable control strategy is to maintain the slip ratio value to remain in the optimal and safe working range of the braking system. In general, the control purpose of the ABS is to set the wheel slip ratio to its optimum range [4-6].

In EV, some ABS systems using mechanical braking (friction), also use regenerative braking in order to save electricity as described in [7]. This system known as regenerative ABS can increase vehicle efficiency. The study results showed that the energy storage achieved by this system ranged from $8 \%-25 \%$ of the total energy used by vehicles, depending on the regulatory cycle and control strategy [8]. Hence this technology has been applied to many kinds of EV. Tur et al. [7] and Mizarei et al. [9] have proposed 
regenerative braking strategies and control methods during normal and sudden braking events, without discussing the ABS scheme in their research.

Regenerative braking system is superior to hydraulic braking in terms of accuracy, speed of response and ease of measurement. However, since regenerative braking system is constrained by many factors such as motor speed, state of charge and battery temperature [10], while friction braking system is still used as a complement. Therefore, it is necessary to develop a braking strategy that coordinates the regenerative torque of the motor and the friction torque of the hydraulic unit, as proposed in [7]. Furthermore, in recent years, advances in actuator technology have led to electro-hydraulic and electro-mechanical braking systems that are capable of continuous modulation of braking torque [2]. Therefore, research on ABS control systems equipped with regenerative braking is a very relevant system to be developed.

ABS control is fairly complicated. The main obstacle that arises when designing ABS control is the nature of nonlinearities and large uncertainties. A number of advanced control approaches have been proposed for ABS, such as fuzzy logic control [10], neural network [11], adaptive control [12], sliding mode control [13] and other intelligent controls. Along with the development of ABS technology that uses electrical components, the chance of errors also increases. In addition, for ABS technology that still uses friction braking (hydraulic) systems other than regenerative braking, mechanical components such as valves, pumps and electric motors in fact have a failure intensity that exceeds electronic components [14]. In this case, no matter how good the control system is, the nominal control system does not have the ability to guarantee the continuity of the whole system during a fault event in its components, such as sensors and actuators. Though the demand for system reliability is very high on ABS related to security issues, passenger safety remains to be a mandatory feature that must be fulfilled, and the reliability of the regenerative ABS system must also be high. Faults that occur, such as in the ABS control system, namely faults in the solenoid valve and speed sensor must be accommodated so that the system continues to work in a safe area. Therefore, it is necessary to build a control system that is able to accommodate the occurrence of faults (with a certain level of error) known as fault tolerant control (FTC).

The advantage offered by FTC technology on regenerative ABS is an increase in system reliability at an economical cost because it does not add any hardware components other than software repair. However, the study results of FTC for braking systems in particular are very few. One of the findings of the literature study is reported by Swaroop et al. [15] who suggested that the impact of the failure of the braking system (sensors and actuators) on electrically controlled vehicles is to inhibit the vehicle's ability to slow down. They used two sets of failure detection filters (each for sensors and actuators) to detect a failure, and observers to reconfigure control signals. Although impact of model inaccuracies, detection error and presence of noise have not been discussed, this scheme is for speed control system, rather than slip control system (ABS). In addition, the use of filter sets makes computational load large even though the system must be realized in real-time, so the time interval between the input and output signals of the system must be reduced as much as possible.

This paper discusses the development of a regenerative ABS - a combination of regenerative braking and mechanical braking - which is equipped with the FTC scheme. Here the slip control system was studied to produce the right braking response despite faults in the sensor and actuator components. The proposed scheme is only based on observers so reduces load computation. It was applied to simulations using a quarter car model.

\section{RESEARCH METHOD}

A quarter car model is the one of vehicle modeling method by considering only one wheel as shown in Figure 1. It has three forces influencing its movement when braking occurs, namely aerodynamic resistance force $(\mathrm{Fa})$ and the braking force $(\mathrm{Fx})$. The equation of the horizontal motion of the car due to the two forces is:

$$
\begin{aligned}
& -\left(F_{a}+F_{x}\right)=m \dot{V} \\
& F_{a}=c_{a} V^{2} \\
& F_{x}=\mu m g
\end{aligned}
$$

with:

$c_{a}=$ aerodynamic constant

$V=\operatorname{vehicle}$ speed $(\mathrm{m} / \mathrm{s})$

$\mu=$ coefficient of road surface friction

The wheel rotation motion model is given by the equation:

$$
\begin{aligned}
g & =\text { gravitational acceleration }\left(\mathrm{m} / \mathrm{s}^{2}\right) \\
m & =\text { one-wheel mass }(\mathrm{kg}) \\
R & =\text { wheel radius }(\mathrm{m})
\end{aligned}
$$


$F_{x} R-T_{b}=J \dot{\omega}$

with: $T_{b}=$ braking torque (N.m) $J=$ moment inertia of one wheel $\left(\mathrm{kg} . \mathrm{m}^{2}\right) \omega=$ angular speed of wheel $(\mathrm{rad} / \mathrm{s})$

Road surface friction coefficient $(\mu)$ could be modelled by the magic equation given by Pacejka and Bakker [16]:

$$
\mu(\lambda, V)=\left[C_{1}\left(1-e^{-C_{2} \lambda}\right)-C_{3} \lambda\right] e^{-C_{4} \lambda V}
$$

with

$C_{1}=$ the maximum value of friction curve

$$
\begin{aligned}
& C_{4}=\text { wetness characteristic value } \\
& \lambda=\text { slip ratio }
\end{aligned}
$$

$C_{3}=$ the friction curve difference between the maximum value and the value at $\lambda=1$

The slip ratio represents the difference between the velocity of the tire circumference and the relative speed of the vehicle against the road surface, which can be expressed in terms of (6):

$$
\lambda=\frac{V-\omega R}{V}
$$

When there is a very strong braking, it can generally cause wheel lockup which means $\omega=0$, so $\lambda=1$. The condition of wheel lockup can extend the stopping distance and cause loss of control towards the direction of motion. Increased wheel slip causes a reduction in tire friction coefficient, $\mu$. Therefore ABS is needed to limit slips to prevent locking on the wheels.

Thus, the control system used on ABS must adjust the amount of braking torque produced by both braking systems. The algorithm for determining the distribution of both systems is shown in Figure 2, which is a modification of that by Guo et al. [17]. When the braking pedal is stepped on, the controller produces the required braking torque value, $T_{b r}$ The condition of the vehicle, when braking starts to be active, will determine the available braking torque of the motor, $T_{\text {mavail }}$. If the required braking torque is smaller than the available braking torque of the motor, then only regenerative braking is activated, ie the motor braking system is run to produce the same braking torque as $T_{m f}=T_{b r}$ If the braking torque required is greater than the available braking torque of the motor, then the motor braking system is run to produce its full capability $T_{m f}$ $=T_{\text {mavail }}$; and the hydraulic braking system is also activated to produce the demand hydraulic braking torque $T_{h f}=T_{b r e q}-T_{m f}$.

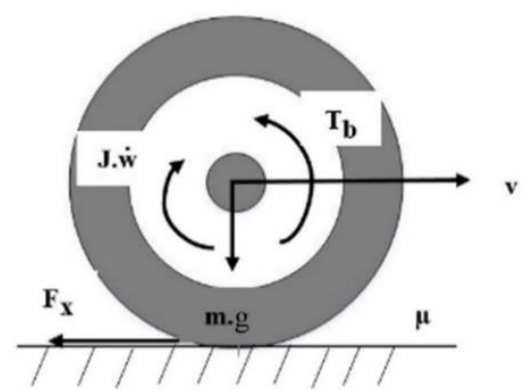

Figure 1. Forces on a quarter car wheel [7]

The regenerative ABS system works by adjusting the braking torque to keep the slip ratio value in accordance with the setpoint. Braking torque that works on regenerative ABS systems is obtained from the braking torque of the motor and hydraulic braking torque as given (7):

$T_{b}=T_{m}+T_{h}$

Available motor braking torque, $T_{\text {mavail }}$, can be calculated by (8):

$$
T_{\text {mavail }}=\frac{T_{m \max } i k_{\omega m} k_{s o c}}{\eta_{t}}
$$

where: 
$T_{\text {mmax }}=$ maximum motor torque $i=$ transmission ratio; $\eta_{t}=$ transmission efficiency

$k_{S O C}=$ weighting factor in the state of charge of battery, the amount of which is determined by:

$$
k_{\text {soc }}=\left\{\begin{array}{cc}
1 & \text { SOC } \leq 0.8 \\
10(0.9-\text { SOC }) & 0.8<\text { SOC } \leq 0.9 \\
0 & 0.9<\text { SOC } \leq 1
\end{array}\right.
$$

$k_{\omega_{m}}=$ the weighting factor due to the low electrical force (voltage) generated when the rotation speed is low, can be expressed as [17]:

$$
k_{\omega_{m}}=\left\{\begin{array}{cc}
0 & \omega_{m} \leq 50 \mathrm{rad} / \mathrm{s} \\
\left(\omega_{m}-50\right) / 50 & 50<\omega_{m} \leq 100 \mathrm{rad} / \mathrm{s} \\
0 & \omega_{m}>100 \mathrm{rad} / \mathrm{s}
\end{array}\right.
$$

Furthermore, the dynamics of the motor braking system can be modeled as a first-order system [18]:

$$
\frac{T_{m}(s)}{T_{m f}(s)}=\frac{1}{\tau_{m} s+1}
$$

with $\tau_{\mathrm{m}}$ being the motor torque time constant.

Hydraulic braking torque is generated by fluid pressure which has first-order dynamics system. So that the dynamic equation of the hydraulic braking system can be written as (12) as given by Paulinus et al. [19]:

$$
\frac{T_{h}(s)}{T_{h f}(s)}=\frac{1}{\tau_{h} s+1}
$$

where $\tau_{\mathrm{h}}=$ the hydraulic torque time constant.

The controller produces a control signal in the form of the required braking torque value, $T_{b r} \mathrm{~A}$ block diagram of this control system is shown in Figure 3. The control algorithm used is sliding mode control (SMC). SMC has been chosen as it is known for its robustness against unmodelled dynamics, parametric uncertainties and external disturbances [20]. The equation of the sliding surface is the setpoint error, i.e.

$$
S(t)=\lambda_{\text {setpoint }}(t)-\lambda(t)
$$

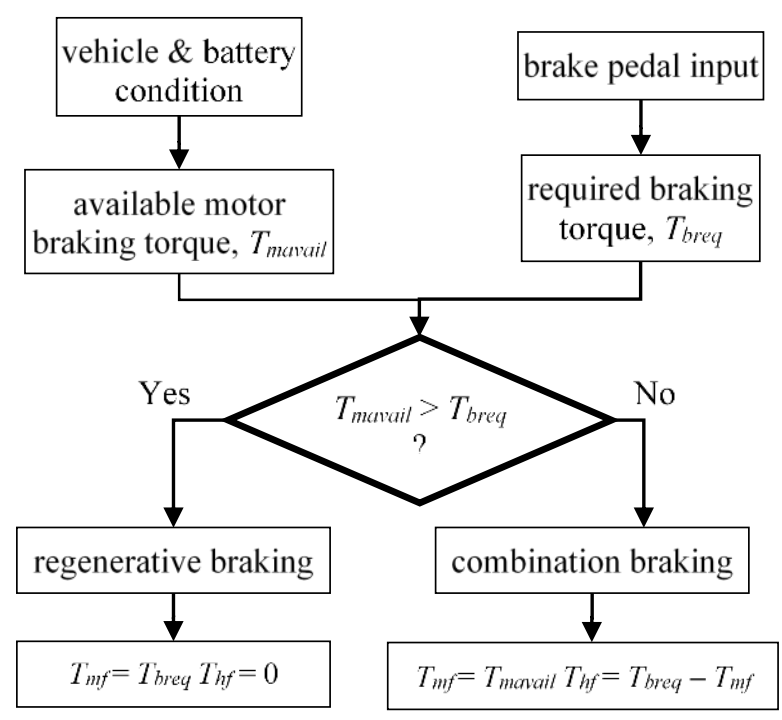

Figure 2. Distribution algorithm of braking torque 


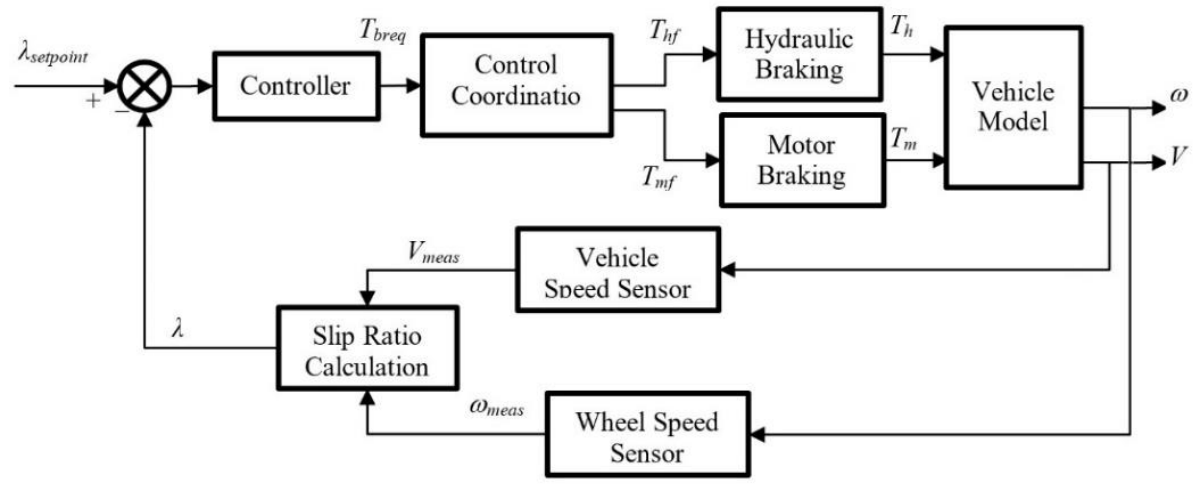

Figure 3. The block diagram of control system for regenerative ABS plant

In order to generate a control signal, this study uses constant rate reaching law described by Liu and Wang [21], which is written as follows:

$$
\dot{S}=-\varepsilon \operatorname{sgn}(S)-k S \varepsilon>0, k>0
$$

with $\varepsilon$ and $k$ being called sliding gain and error gain respectively; while signum function (sgn) is defined as:

$$
\operatorname{sgn}(S)=\left\{\begin{array}{cc}
1 & S>0 \\
0 & S=0 \\
-1 & S<0
\end{array}\right.
$$

Next, the equation of the control signal in the from of required braking torque is given by:

$$
T_{\text {breq }}=T_{\text {beq }}+T_{\text {bhit }}
$$

$T_{b e q}$ is the estimate of the equivalent control input which can be obtained from (17)

$$
T_{b e q}=R \widehat{F}_{x}-\frac{J \widehat{\omega}}{\widehat{m} \widehat{V}}\left(\widehat{F}_{x}+\widehat{F}_{a}\right)
$$

with $\widehat{F}_{x}$ dan $\widehat{F}_{a}$ being estimation values of friction and aerodynamic force respectively, from equation (2) and (3). Both these estimates contain the uncertainties happened in the mass of vehicle, $m$, which changes with the number of passengers and the luggage weight; as well as in the friction coefficient, $\mu$, depending on road surface condition.

The ranges of variation of $m$ and $\mu$ are set as $m_{\min } \leq m \leq m_{\max }$ and $\mu_{\min } \leq \mu \leq \mu_{\max }$. This study considers the estimated values of these parameters respectively as the mean value given as

$$
\widehat{m}=\frac{m_{\max }+m_{\min }}{2} \widehat{\mu}=\frac{\mu_{\max }+\mu_{\min }}{2}
$$

$T_{b h i t}$ is the hitting control signal to satisfy sliding condition despite uncertainty on the dynamics of $T_{\text {beq }}$, so the controller will perform much robustly. The hitting control signal is defined:

$$
T_{\text {bhit }}=\frac{J \widehat{V}}{R}[\varepsilon \operatorname{sgn}(S)+k(S)]
$$

where $\operatorname{sgn}(S)$ is defined in (15).

In the ABS system, there are two sensors used, namely wheel speed sensor and vehicle speed sensor. Both measurements determine the calculation of the slip ratio of the vehicle. Thus, faults in these two sensors can cause a deterioration in the response of the control system. Although SMC is a robust controller, sensor faults that can be accommodated by this controller are of limited value according to the specified level of uncertainty. This study proposes an observer approach to provide estimates of the true output value for SMC. Here there are three PI observers which are connected as shown in Figure 4. 
The proposed observer is built based on the plant model. For wheel speed estimation, (4) is used in the model. The demand braking torque can be obtained by knowing the control signal, while the friction force $F_{x}$ is not known. Therefore, $F_{x}$ is considered a disturbance and must be estimated besides the wheel speed sensor fault. Thus, observability condition cannot be fulfilled if both disturbances are estimated. In this study, $F_{x}$ is chosen as an estimated variable, for two reasons. First, $F_{x}$ is needed to estimate vehicle speed as will be explained in the next paragraph. Second, the sensor fault in a wheel can be considered as perturbations of wheel inertia, $J$, in which $J$ is smaller than the vehicle mass, $m$, [22], thus the impact of this uncertainty is not large. The observer algorithm for estimating $F_{x}$ is built using proportional - integral (PI) structure as explained in the work by Tsai et al. [23], that is PI compensator employed in the closed-loop observer stage. Hence, the PI observer can be used to estimate both the true value of system states (by means of proportional gain, $K_{p} \omega$ ) and disturbances (using integral gain, $K_{i} \omega$ ). The observer for estimation $F_{x}$ is using the observer equation given below:

$$
\begin{aligned}
& \dot{\hat{\omega}}=\frac{1}{J}\left(-T_{b}+R \widehat{F}_{x}+K_{p \omega}\left(\omega_{\text {meas }}-\widehat{\omega}\right)\right) \\
& \dot{\hat{F}}_{x}=K_{i \omega}\left(\omega_{\text {meas }}-\widehat{\omega}\right)
\end{aligned}
$$

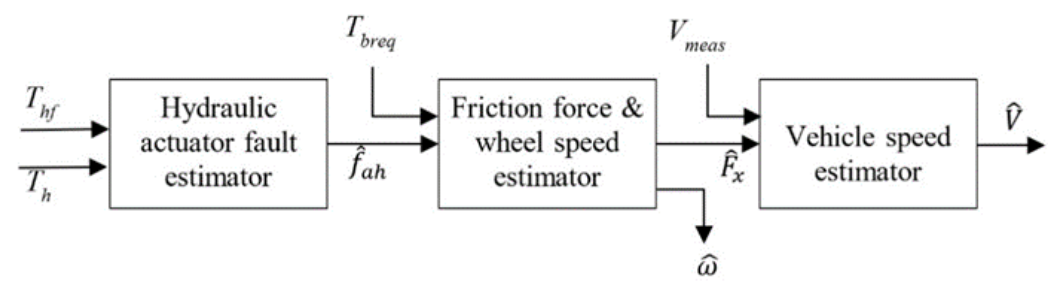

Figure 4. The structure of the proposed observers

The observer for vehicle speed estimation is built by referring to (1). In order for sensor fault of vehicle speed $f_{s v}$ appears in the state equation, then an augmented state provided by Indriawati et al. [24] is used: $\dot{z}=A_{z}\left[V_{\text {meas }}-z\right]$.

Next the proposed observer is then developed based on augmented state space model with PI structure. The prevailing observer equation is:

$$
\begin{aligned}
& \dot{\hat{V}}=\frac{1}{m}\left(-c_{a} \hat{V}^{2}-\hat{F}_{x}+K_{p v}(z-\hat{z})\right) \\
& \dot{\hat{f}}=K_{i v}(z-\hat{z}) \\
& \dot{\hat{z}}=A_{z}\left(\hat{V}+\hat{f}_{s v}-z\right)+\dot{\hat{f}}_{s v}
\end{aligned}
$$

The regenerative ABS braking system involves two actuators, namely a hydraulic actuator and a motor actuator [25]. However, because the braking torque of the motor is much smaller than the hydraulic braking torque, the impact of the motor braking actuator fault is not as significant as the impact of the hydraulic braking actuator fault. Therefore, in this study, only the fault of hydraulic actuator is considered. Actuator fault can be considered as an interference that appears in the state equation. Thus, estimation of hydraulic actuator fault $f_{a h}$ is done in the same way as the estimation of friction force $F_{x}$, but using a hydraulic system dynamic model or (11). The observer equations are:

$$
\begin{aligned}
& \dot{\widehat{T}}_{h}=T_{h f}+\hat{f}_{a h}+K_{p h}\left(T_{h}-\hat{T}_{h}\right) \\
& \hat{f}_{a h}=K_{i h}\left(T_{h}-\hat{T}_{h}\right)
\end{aligned}
$$

The fault tolerant scheme proposed in this study consists of two ways, each to overcome a sensor fault and an actuator fault. To overcome a sensor fault, the state estimation results of the observer are used to replace the measured results. Thus, SMC receives information about the true state that occurs in the vehicle not the wrong measurement results. Whereas to compensate for actuator fault, the estimation of actuator fault is used to correct the control signal $\mathrm{T}_{\mathrm{hf}}$ through a subtraction operation. Overall, a fault tolerant scheme changes the structure of the SMC system (see Figure 3) to the one as shown in Figure 5. 


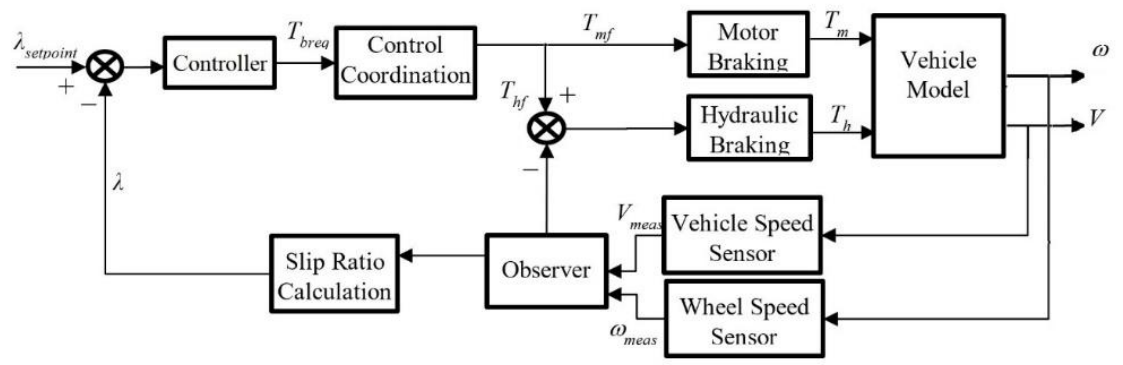

Figure 5. The block diagram of active fault tolerant SMC for regenerative ABS plant

\section{RESULTS AND DISCUSSION}

To demonstrate the effectiveness of the proposed design of active fault tolerant SMC for regenerative ABS, the computer simulation is developed. In this simulation, the type of faults is bias fault and the assumed road condition is a high friction road (dry asphalt). The parameters of the regenerative ABS system under study are given in Table 1 . The desired slip ratio is 0.2 . The initial vehicle velocity was set 16.7 $\mathrm{m} / \mathrm{s}(60 \mathrm{~km} / \mathrm{h})$, thus the initial wheel speed velocity was $50.6 \mathrm{rad} / \mathrm{s}$. The parameter values of the controller are $\varepsilon=0.1$ and $\mathrm{k}=20$.

The SMC can prevent vehicle skid as shown in Figure 6 and Figure 7. These figures are evaluated under the nominal conditions (no fault) at times before $0.3 \mathrm{~s}$, and after that, faulty condition, namely hydraulic actuator fault of -200 N.m for Figure 6 and vehicle speed sensor fault of $2 \mathrm{~m} / \mathrm{s}$ for Figure 7. As can be seen in these figures, the active fault tolerant SMC (AFTSMC) yield marked anti-slip performances under nominal and faulty condition, while the SMC cannot follow the setpoint anymore under faulty condition. The AFTSMC keeps the slip ratio at the setpoint value thereby improving braking stability and passenger comfort, even for the simultaneously occurred faults as described in Figure 8: the hydraulic actuator fault starts at time of $0.3 \mathrm{~s}$, and continuing the vehicle speed sensor fault occurred at time of $0.4 \mathrm{~s}$. Futhermore, there is no transition time for AFTSMC to accommodate the sensor fault and less $0.1 \mathrm{~s}$ for AFTSMC to return the response back to the setpoint. This indicates that the proposed scheme does not require large computational time.

Figure 9 shows the wheel speed and vehicle velocity with the AFTSMC-based ABS and the SMCbased ABS for the same case of Figure 8. As can be seen, the proposed SMC try to stop the car quickly and the variation of the vehicle velocity with the AFTSMC is similar to the nominal controller (without faults). The performance of the ABS with the AFTSMC is far better than the ones with the SMC. Comparing to the SMC controller, the AFTSMC one produces faster stopping. This is because the braking torque of the AFTSMC continues to grow until the vehicle stops, while the braking torque of the SMC decreases, as seen in Figure 10. Furthermore, the braking torque of the SMC is more sensitive to the faults (at $0.3 \mathrm{~s}$ for the actuator fault and $0.4 \mathrm{~s}$ for the vehicle speed sensor fault) than one of the AFTSMC. This proves that the AFTSMC is more robust against actuator and sensor faults.

Table 1. Parameters used in the simulations

\begin{tabular}{ccr}
\hline Symbol & Description & Value \\
\hline$m$ & mass of the quarter vehicle $(\mathrm{kg})$ & 342.5 \\
$J$ & wheel rotational inertia $(\mathrm{kg} . \mathrm{m} 2)$ & 3.5 \\
$R$ & wheel radius $(\mathrm{m})$ & 0.33 \\
$c_{a}$ & aerodynamic constant & $0.2921 / 4$ \\
$T_{\max }$ & maximum motor torque $(\mathrm{Nm})$ & 150 \\
$i$ & transmission ration & 4.1 \\
$\eta_{t}$ & transmission efficiency & 0.95 \\
$\tau_{h}$ & the hydraulic torque time constant (s) & 0.01 \\
$\tau_{m}$ & the motor torque time constant (s) & 0.005 \\
$C_{l}$ & the maximum value of friction curve & 1.029 \\
$C_{2}$ & the friction curve shape & 17.16 \\
$C_{3}$ & the friction curve difference between the maximum value and the value at $\lambda=1$ & 0.523 \\
$C_{4}$ & wetness characteristic value & 0.03 \\
\hline
\end{tabular}




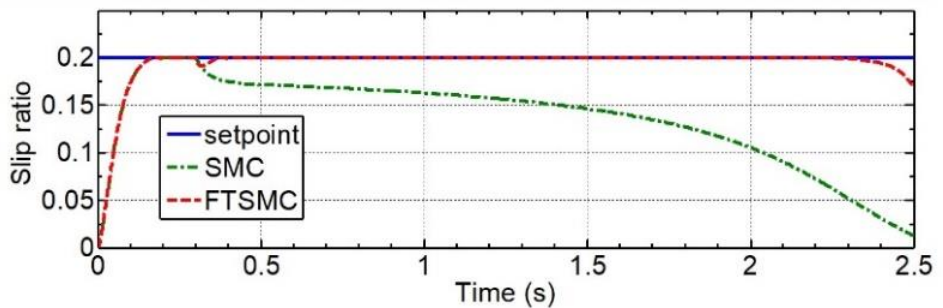

Figure 6. Comparison of the slip ratio responses for single actuator fault case

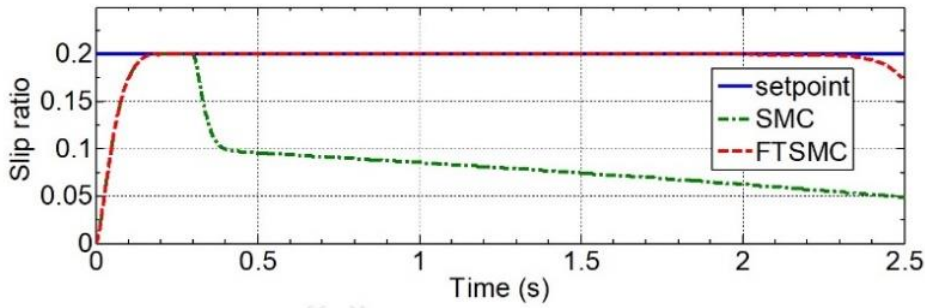

Figure 7. Comparison of the slip ratio responses for single vehicle speed sensor fault case

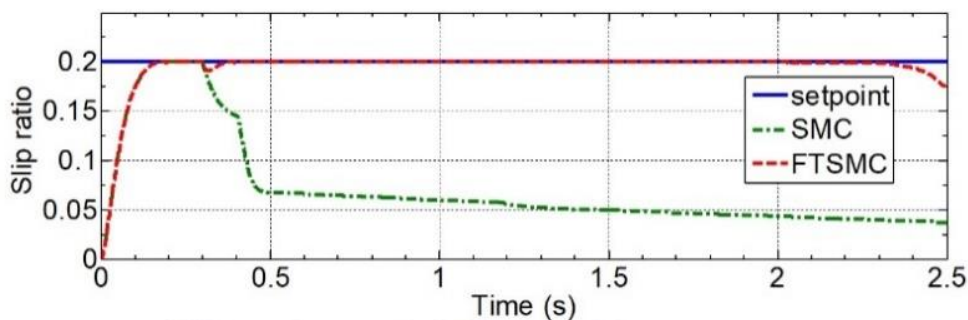

Figure 8. Comparison of the slip ratio responses for simultaneously actuator and sensor fault case

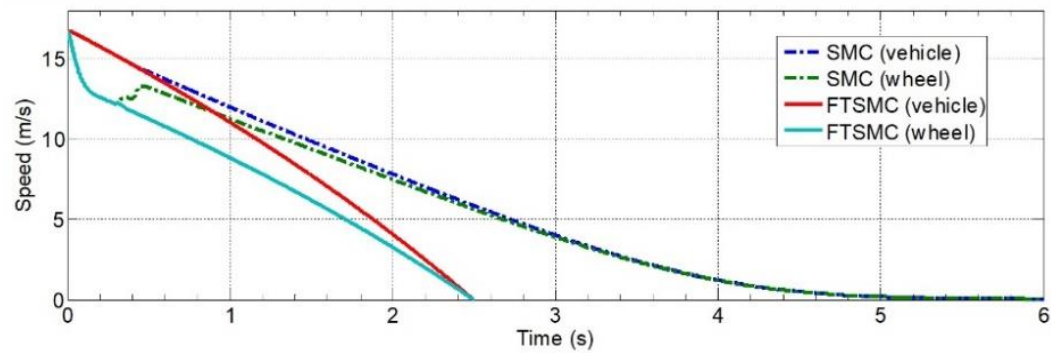

Figure 9. Comparison of the speed responses for simultaneously actuator and sensor fault case

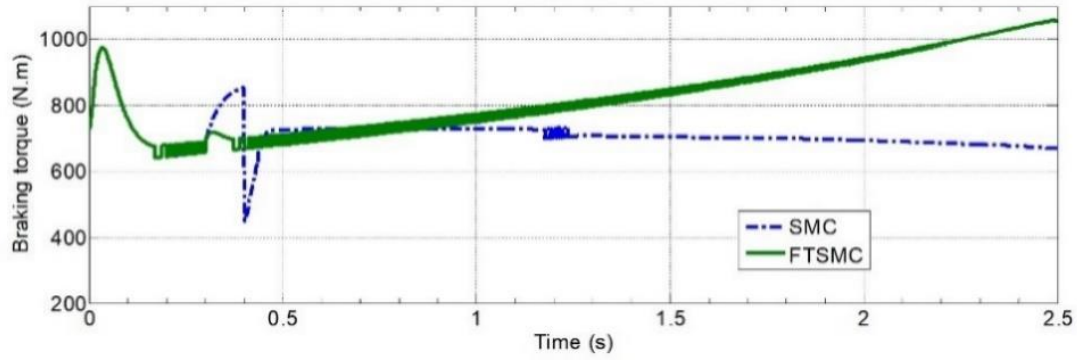

Figure 10. Comparison of the braking torque for simultaneously actuator and sensor fault case 4. CONCLUSION

Sensor/actuator fault tolerant sliding mode control for anti-lock braking ... (Bambang L. Widjiantoro) 
This paper deals with application of fault tolerant control scheme in SMC system for regenerative ABS technology. This scheme improves the conventional SMC approach with fault-tolerant capabilities to prevent electric vehicles from slipping in many general steering situations. Braking is simulated to occur regeneratively and also mechanically, if needed. In this case, the controlled variable is the slip ratio by manipulating the braking torque. Three PI observers which estimate the friction torque, the vehicle speed sensor fault, and the hydraulic actuator fault have been employed in this proposed scheme. As shown in the simulation results, the proposed anti-slip system offers an effective performance in maintaining the driving stability under probable fault condition. Therefore, the steering safety of the electric vehicles will be further improved in the near future.

\section{REFERENCES}

[1] Yonggon L., Zak S. H., "Designing a Genetic Neural Fuzzy Antilock-Brake-System Controller," IEEE Transaction on Evolutionary Computation, vol. 6, no. 2, pp. 198-211, 2002.

[2] Sergio M. S., Mara T., "Active Braking Control Systems Design for Vehicles," London: Springer, pp. 3-17, 2010.

[3] Kim J., Lee J., "Real-Time Estimation of Maximum Friction and Optimal Slip Ratio Based on Material Identification for a Mobile Robot on Rough Terrain," 13th International Conference on Control, Automation and Systems (ICCAS), pp. 1708-1713, 2013.

[4] Wang W. Y., Li I. H., Tsai C. P., Su S. F., Hsu S. B., "Dynamic Slip-ratio Estimation and Control of Antilock Braking System Using an Observer-Based Direct Adaptive Fuzzy-Neural Controller," IEEE Transaction on Industrial Electronics, vol. 56, no. 5, pp. 1746-1756, 2009.

[5] Patil C. B., Longoria R. G., Limroth J., "Control Prototyping for Anti-lock Braking Control System on a Scaled Vehicle," IEEE Conference on Decision and Control. Hawaii, vol. 5, pp. 4962-4967, 2004.

[6] Oudghiri M., Chadli M., Hajjaji A. E., "Robust Fuzzy Sliding Mode Control for Antilock-Braking-System," International Journal Science Technology Automotive Control, vol. 1, no. 1, pp. 13-28, 2007.

[7] Tur O., Ustun O., Tuncay R. N., "An Introduction to Regenerative Braking of Electric Vehicles as Anti-lock Braking System," IEEE Intelligent Vehicles Symposium, pp. 944-948, 2007.

[8] Yao J., Zhong Z. M., Sun C. Z., "A Fuzzy Logic based Regenerative Braking Regulation for a Fuel Cell Bus," IEEE International Conference on Vehicular Electronics and Safety, pp. 22-25, 2006.

[9] Mirzaei A., Moallem M., Dehkordi B., "Design of an Optimal Fuzzy Controller for Antilock-Braking-Systems," IEEE Vehicle Power and Propulsion Conference, pp. 823-828, 2005.

[10] Peng D., Zhang Y., Yin C. L., Zhang J. W., "Combined Control of a Regenerative Braking and Antilock Braking System for Hybrid Electric Vehicles," International Journal Automotive Technology, vol. 9, pp. 749-757, 2008.

[11] Lin C. M., Hsu C. F., "Neural-Network Hybrid Control for Antilock Braking Systems," IEEE Transactions on Neural Networks, vol. 14, no. 2, pp. 351-359, 2003.

[12] Yu J. S., "A Robust Adaptive Wheel-Slip Controller for Antilock-Brake-System," Proceedings of the 36th IEEE Conference on Decision and Control, vol. 3, pp. 2545-2546, 1997.

[13] Zhou Z., Mi C., Zhang G., "Integrated Control of Electromechanical Braking and Regenerative Braking in Plug-in Hybrid Electric Vehicles," International Journal of Vehicle Design, vol. 58, pp. 223-239, 2012.

[14] Manzone A., Pincetti A., De Costantini D., "Fault Tolerant Automotive Systems: An Overview," Proceedings Seventh International On-Line Testing Workshop, pp. 117-121, 2001.

[15] Swaroop D., Gerdes J. C., Hedrick J. K., "Fault Tolerant Control of Automatically Controlled Vehicles in Response to Brake System Failures," IEEE Int. Conf.on Control Applications, pp. 705-710, 1997.

[16] Pacejka H., Bakker E., "The Magic Formulae Tire Model," The 1st Int. Colloquium on Tire Models for Vehicle Dynamics Analysis, pp. 1-18, 1991.

[17] Guo J., Jian X., Lin G., "Performance Evaluation of an Anti-Lock Braking System for Electric Vehicle with a Fuzzy Sliding Mode Controller," Energies, vol. 7, no. 10, pp. 6459-6476, 2014.

[18] Sakai S., Sado H., Hori Y., "Anti-skid Control with Motor in Electric Vehicle," The 6th International Workshop on Advanced Motion Control, pp. 317-322, 2000.

[19] Paulinus C. E., Ferdinand A. A., Muoghalu C., Ifeoma H. E., "Linear Slip Control for Improved Antilock Braking System," Int. Research Journal of Advanced Engineering and Science, vol. 3, no. 1, pp.198-206, 2018.

[20] Hung J., Gao W., Hung J., "Variable Structure Control: A Survey," IEEE Transactions on Industrial Electronics, vol. 40, no. 1, pp. 2-22, 1993.

[21] Liu J., Wang X., "Advanced Sliding Mode Control for Mechanical Systems," Beijing: Tsinghua University Press and Berlin: Springer-Verlag, pp. 31-35, 2012.

[22] Hu J. S. C., "Design of Robust Stabilization and Fault Diagnosis for An Auto-balancing Two-wheeled Cart," Advanced Robotics, vol. 22, pp. 319-338, 2008.

[23] Tsai M. C., Tseng E. C., Cheng M., "Design of A Torque Observer for Detecting Abnormal Load," Control Engineering Practice, vol. 8, pp. 259-269, 2000.

[24] Indriawati K., Agustinah T., Jazidie A., "Robust Observer-based Fault Tolerant Tracking Control for Linear Systems with Simultaneous Actuator and Sensor Faults: Application to a DC Motor System," International Review on Modelling and Simulation, vol. 8, no. 4, pp. 410-417, 2015.

[25] Kumar S. K., et al., "Fuzzy Logic based Integrated Control of Anti-lock Brake System and Collision Avoidance System using CAN for Electric Vehicles," IEEE Conference on Industrial Technology, pp. 1-5, 2009. 


\section{BIOGRAPHIES OF AUTHORS}

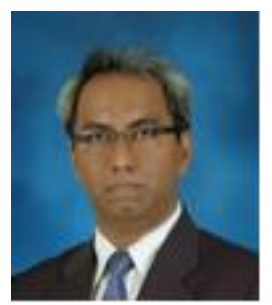

Bambang L. Widjiantoro was born in Jember, Indonesia, in 1969. He awarded a Doctorate and a Master in Instrumentation and Control Study Program from Institut Teknologi Bandung (ITB), Indonesia in 2005 and 1999 respectively, as well as a Bachelor degree in Engineering Physics from ITS in 1993. His research interests include industrial control system and process control. He is currently a senior lecturer of control and instrumentation division, Engineering Physics Department, ITS.

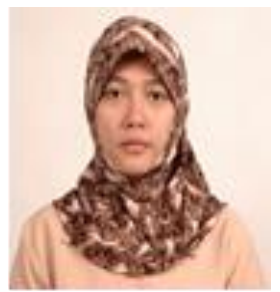

Katherin Indriawati was born in Jember, Indonesia, in 1976. She received the B.Sc. degree in engineering physics and the M. Sc degree in instrumentation \& control, from Institut Teknologi Bandung (ITB), Bandung, Indonesia, in 1998 and 2005, respectively. She has taken the Ph.D. degree in 2016 at Institut Teknologi Sepuluh November (ITS), Surabaya, Indonesia. After receiving the B.Sc. degree, she joined Engineering Physics Department, ITS. Her research interests include supervisory control, fault tolerant control, fault detection, diagnosis and decision-making scheme. Dr. Indriawati is a member of the IEEE 